\title{
VIEWS OF FOSTERCHILDREN ABOUT CONTACTS WITH PARENTS AND RELATIVES
}

\section{Ljiljana Skrobić1}

Original scientific paper

Center for Foster Care and Adoption Belgrade, counselor and implementator of educational programs for foster parents

Received: 17.01 .2016

Accepted: 22.02.2016
UDC:364-782.42

$364.65-053.2$

\begin{abstract}
This paper presents the results of research on the views of children about contacts with their birth parents and relatives. The views of children are seen through their experience in contacts and the wishes of children that relate to future contacts. The results show that children in foster care have positive attitude to the contacts and that no child wants to terminate the contacts maintained with the parents and relatives. A number of children want a greater number of contacts, or to establish contact with persons with whom there is no actual contact. Also, most of the children had the opportunity to participate in the planning and realization of contacts and the children who participated recognize their participation as an important issue.
\end{abstract}

Keywords: foster care, children, contacts, parents, relatives

\section{INTRODUCTION}

"For better and worse, they (family members) are his roots to the past, his support and foundation. When he is separated from them, he feels that he has lost a part of himself" (Littner, 1975: 177).

The literature and practice has confirmed the importance of maintaining multiple contacts of children in foster care with their parents and relatives. Contacts are child's right, as a preparation for the return to their biological families, a way of preserving identity and continuity and have an important role in the lives of children in foster care and contribute to their growth and development (Taplin, 2005). Because of the specificity of each child and family circumstances, in relation to what effect they have, contacts may be appro- priate or they can hurt the child. A good assessment of the child and the parents and / or relatives is crucial when making decisions about contacts. The decision on the contacts should take into account the purpose of the contacts, safety of the child, the relationship with significant people, especially the views and wishes of the child.

In a broader sense contacts are defined as direct or indirect communication between a child in care and his significant others (Quinton et al., 1997). Direct contacts are represented by personal encounters, while indirect contacts take place through the exchange of letters, telephone calls, correspondence via the Internet. In this paper the term contacts include both direct and indirect contacts of children in foster care with their parents and relatives with whom the children do not live.

\footnotetext{
Correspodence to: parents

PhD student, Faculty of Political Sciences, University of Belgrade, Serbia

Janka Katića 25, 11400 Mladenovac, Serbia

Phone: 00381642711679

E-mail: 1jiljana21@gmail.com
}

Ljiljana Skrobić, Center for Foster Care and Adoption Belgrade, counselor and implementator of educational programs for foster 
Number of children in foster care in the Republic of Serbia continuously grew in the period 2009-2014. In 2014, 6080 children and young people were in foster care (Republic Institute for Social Protection, 2015). There are data about contacts with relatives for 2637 children who were placed in foster care and supported and monitored by centers for foster care and adoption from Belgrade, Nis, Ćuprija, Kragujevac, Miloševac by the end of 2014 . Based on available data, $35 \%$ of children once a month have contact with relatives, 14 , $5 \%$ have contact every three months, while $8.5 \%$ children have contact with relatives once in six months. The most common sites of maintaining contacts are within biological and foster families placement. A number of children have no contact with relatives $(\mathrm{N}$ $=23 \%$ ), while $4.5 \%$ of children have no relatives (Republic Institute for Social Protection, 2015). Based on these data, it is unclear with whom the children of relatives maintain contact, whether relatives with whom the children have contact include relatives who are also their foster parents. Also, the information on the reasons for failure to maintain contacts as well as information on the content and effects of contacts are lacking.

Based on the results of the survey which covered 347 children and youth placed in foster families and institutions in the social protection system, we see that in the maintenance of contacts a large number of data is missing in the files of children (Žegarac, 2014). Two thirds of children $(61.4 \%)$ maintain contacts with parents and /or relatives. Children and young people usually maintain contacts with siblings $(35.2 \%)$, then with their mother (30\%) and father $(21.3 \%)$.

Research findings show that children have different opinions about the extent to which they want to be within biological or foster family and want contacts with biological family members, but still in any case all children want to have their opinions respected (Sinclair, 2005). Studies that have dealt with what children want to change in connection with their placement show that children want more contact with their family, some children with their parents, and some with siblings (Sinclair, 2005). It is important for children that professionals listen to their views (Herrick $\&$ Piccus, 2005). When children do not have contacts, they want to have information on important persons and consider that the obligation of professionals is to oblige (Ofsted, 2009). Although participation of children in alternative care indecision-making process is imperative, it seems that children are not always given the opportunity to participate although that it is their wish, and need to be more involved in planning and decision-making (Cleaver, 2000; CRETE Foundation 2001; Mason \& Gibson, 2002; Ofsted, 2009).

\section{THE METHODOLOGICAL FRAMEWORK OF THE RESEARCH}

Questionnaire about contacts of children in foster care with their parents and relatives was conducted on a sample of 100 children aged 7-14 who are placed in foster families in Belgrade (including larger urban community-Mladenovac, Lazarevac and Obrenovac). Schoolchildren were selected to enable closer understanding of dynamics of contacts for children of that age and their views on the contacts. Counselor of Center for Foster Care and Adoption Belgrade completed a questionnaire about the existence and characteristics of contacts for each individual child. The results show that $88 \%$ of children achieved some form of contact with their parents and/or relatives. More than half of children have contacts with two, three or more people. Slightly more than half of children $(53 \%)$ have contacts with relatives, half of the children have contacts with their mother, while contacts with the father (35\%) and siblings (37\%) exist in the approximate number of children. The same relationship exists when it comes to personal meetings and telephone contacts. Communication via the Internet and the exchange of letters are underrepresented. Frequency of contacts is less than once a month.In addition to these results, researches are interested in the opinion of children on the contacts and accordingly a qualitative part of the research was implemented in 13 children which participated from the total sample. Two focus groups were formed on the basis of age of the children due to the assumption of researchers that the children will feel more comfortable and be more willing to talk in the presence of children who are close to their age, rather than in the presence of children who are older than them. One group consisted of children aged 7-10, and the other children of 11-14 years. Groups were sexually heterogeneous ( 5 boys and 8 girls). The average age of children was 10.6 years old. In each group there were two siblings. All children who participated received the written consent of guardians and children gave oral agreement. Focus groups, after obtaining consent, were recorded with voice recorder and then transcribed, and participants were marked with a code in order to preserve anonymity and privacy. Answers of children were sorted by thematic analysis, whereby previously defined topics were taken as a starting framework for thematic categorization of children's narratives. 
RESULTS OF THE RESEARCH EXPERIENCES OF CHILDREN IN CONNECTION WITH THE CONTACTS

Of the total number of children who participated in focus groups all children have contacts with some of the parents and / or relatives. Most children have contacts with their mother $(\mathrm{N}=11)$. Approximate number of children have contacts with siblings $(\mathrm{N}=7)$ and fathers $(\mathrm{N}=6)$. One child has contacts with other relatives (grandmother, uncle, aunt). In contrast the findings of the whole sample research of 100 children for the majority of children who have contacts with relatives in the focus groups contact with relatives were under represented. In both cases, contacts with the mother are present for a large number of children, as well as the approximate ratio contacts with fathers and siblings. A large number of children $(\mathrm{N}$ =9) have contacts with several persons, in various combinations (both parents, parents and siblings, parents and other relatives). Predominant form of contacts arepersonal meetings and telephone contacts as a form of contact. Both of these options correspond to the findings of the entire sample. For all children who participated in the focus groups personal contact with significant people were present. Almost half of them $(\mathrm{N}=7)$ have telephone contacts (calls and text messages), and three children communicate via the Internet, whereas the social network Facebook is primarily used with siblings. Telephone and contacts via the internet are realized daily or weekly.

Children who are in contacts with several important people do not have contacts with everybody equally often, especially when it comes to personal contacts. These results, as well as the previous one, show that the frequency of less than a month is most common. Nearly half of the children $(\mathrm{N}=6)$, regardless of whether they are in contacts with one or more people, make contactsless frequently than once a month. The same number of children $(\mathrm{N}=4)$ have bi-weekly and monthly contacts. Two children have weekly contacts, and only one boy has daily contact with his father, who lives close by.

Some of the children gave the exact days and dates when, according to the plan, they see their parents and relatives:

"On the first Tuesday each month, I see mom", (girl, ten years old).

"Not every Monday. We see each other on Monday, then we miss the second Monday and third we see each other", (boy, nine years old).

More than half of children $(\mathrm{N}=8)$ have contacts with parents and relatives in the premises of the centers for social work. What is characteristic for their interpretation of the venue of the contacts is that they all state that it is happening "in the office":

"I am in an office", (girl, nine years old).

Almost half of the children who participated $(\mathrm{N}=$ 6) have contacts in the biological family, (they visit their parents and relatives) while the same number of children $(\mathrm{N}=5)$ have contacts in a foster family or elsewhere in the city (park, restaurant, zoo). Some of the children have contacts in several places (e.g. with brother in the city with mother in the premises of the center, with parents sometimes in the premises of the center, sometimes in the city).

Contacts that are held in the premises of centers for social work last for an hour, while contacts elsewhere last for several hours:

"We are together all day", (boy, ten years old).

During the contacts larger number of children in this research $(\mathrm{N}=8)$ are alone with parents and relatives for the whole or part of the contacts, while professionals from the centers for social work or foster parents attended the contacts for whole time $(\mathrm{N}=5)$.

Almost all children $(\mathrm{N}=11)$ spend the time during contacts in joint activities with parents and relatives. The most commonactivities are drawing $(\mathrm{N}=4)$, then taking a walk and a playing together $(\mathrm{N}=3)$, going to a restaurant and a zoo $(\mathrm{N}=2)$. Two boys (siblings) and girls do not indicate specific actions during the contact.

"My mom always brings something, sometimes it is a puzzle, and then piece the puzzle and talk about something. Sometimes there's a lot of paper, so we draw to one another", (girl, ten years old).

"For example, we come to the Center, they (parents) come to pick us up and then they ask us where we want to go and we choose. We usually go for a walk, sometimes we go with them to meet relatives. Since we have not seen each other for a long time, we get to know each other again. We say what we like, what we like to eat, to wear. We talk about everything", (girl, twelve years old).

Children said how their contacts with parents and relatives look like. Contacts that are taking place in the premises of the center for social work are reduced to a conversation or a shared drawing, while contacts elsewhere offer more content and features to spend quality time as children themselves noticed. 
The girl who had the opportunity to go for her birthday with her mom, foster mother and the case manager, saysit was better than the contacts in the office. Feelings are a subject that not all children want to talk about. Feelings are divided into three segments, feelings before, during and after the contacts. Feelings before contacts can be classified into three groups: positive, neutral and negative. Positive feelings are present with the majority of children $(\mathrm{N}=$ 10) and they describe that they feel happy, beautiful, excited and can hardly wait for contacts. Several children $(\mathrm{N}=4)$ were neutral in the sense that they said about that they do not feel anything, they do not care or they feel normal. These feelings occur in children who have continuous contacts, so that they can be connected to the predictability of contacts. Children have the experience, perception of security and certainty that they developed due to the possibility to maintain regular and stable contacts.

"I do not care. In fact, I know I'll see him again", (girl, thirteen years old).

Negative feelings priorto contacts have occurred with a boy who feels anger as a dominant feeling in relation to the parents.

"I do not really look forward contacts. I am mostly angry", (boy, thirteen years old).

However, when it comes to contacts with his brother then he talks about positive emotions. A small number of children $(\mathrm{N}=6)$ were talking about how they feel during the contacts. Positive feelings dominate and children formulated them as "interesting", "super", "beautiful", "best".

"I feel interesting because my mom tells me stories about the time when I lived with her, so It's nice to hear what I was like, what I liked doing", (girl, nine years old).

"When I first saw my mother, she was shaking, and I cried because I was happy", (girl, ten years old).

Boy who feels anger before contacts keeps it in the course of contacts with parents.

After contact children show ambivalent feelings. They are happy because they saw their loved once, but there is also a sense of sadness that the contact is finished.

"When I leave them I want to come back again", (boy, ten years old).

"Well, yeah, I'm kind of sad that I am not with her whole a time. Sometimes I would like to visit her, but I do not know where she lives. And then I ask foster mother will take me, and she says she does not know and she will ask the center. It is not clear to mewhy someone else decides when I can see my mom", (girl, ten years old).

"After ward I'm sad because he is gone, and I want more", (boy, ten years old).

More than half of children $(\mathrm{N}=8)$ talk to foster parents about contacts and share their feelings and impressions. Foster parents's support is perceived as important.

"I talk to foster parents about it. And then they tell me what I did wrong and what I did correctly. It means a lot to me to share with them, then it's much easier", (girl, thirteen years old).

More than half of children $(\mathrm{N}=7)$ state that there are no changes in their lives after contact. Three children notice changes in school (one positive and two negative changes), and one child notice negative changes in the relationship with the foster parents. Two children did not comment on the changes after the contact.

"I do better at school because my parents say:" Learn in school to be your own man, and I obeya little", (girl, twelve years old).

"I do not like to do a lot of homework after that because I'm always think about D. (mom) and I want to go somewhere with her", (girl, nine years old).

The girl who said that it was important to her to exchange impressions with foster parents, said that the relations with them changed if they say something bad about her parents, and it has happened in the previous period.

"I do not like it when someone (foster) say that my parents are this and that. Some how I do not feel well about it. They are still my parents. Then I am different to foster parents. I do not talk to them, in fact, we communicate less. Do not get out of the room to be with them, I am mainly on my own and I think about that moment", (girl, twelve years old).

Children talked about the contacts which they remember as the most beautiful. Most often these are gatherings (such as birthday parties, New Year), walking, going to the zoo.

"It was my birthday. As a gift I got a big bear with $a$ heart and a poem. Yeah, my mom wrote my the poem. It starts with "May your eyes never see sorrow". In the end she wrote "Love, Mom" and drew three hearts that have eyes and mouth and angel wing", (girl, ten years old).

"The last contact was with my mom, dad and older brother. It was nice because we all got together and talked about us. There was no argument, there was no shouting, we all laughed and we were happy. That was really nice somehow", (girl, twelve years old). 
A number of children $(\mathrm{N}=5)$ when talking about negative experiences with contacts, referit to the individual situations of conflicts with parents and relatives or conflicts between adults which caused fear and discomfort in children. Brother and a sister recounted contact with the family as a negative experience. During the contact they talked honestly about their feelings which caused anger and outrage among parents. In children, the backlash sparked fear of parents. While the girl was ready to give parents another chance, the boy does not want to. The same number of children $(\mathrm{N}=5)$ states that, in connection with contacts all went well and that they have no negative experiences. Three children did not comment in relation to this issue.

"We said everything we feel. They (parents) got angry at us and started shouting. The two of us felt embarrassed and surprised because we did not expect that reaction. That kind of reaction caused fear of parents", (girl, twelve years old).

"That day I got mad at them and I can notgive them another chance. I'm seeing them just because of my brother, not because of them. When I saw their true face ,so to speak, since that day I have been thinking that they are pretending to be nice, but when we return to live with them, it is going to be another story. I do not want that to happen, and to only then realize that I made a mistake. I would like to correct it immediately", (boy, thirteen years old).

In relation to the dimension of time, about two thirds of children $(\mathrm{N}=8)$ state that there is no difference in contacts before and contacts now. One child stated that there has been improvement of the relationship with his brothers and his mother over time. Three children did not commentin relation to this issue.

\section{THE WISHES OF CHILDREN WITH REGARD TO CONTACTS}

Almost the same number of children $(\mathrm{N}=4)$ wish for the contact frequency to remain the same and/ or for the contacts to happen more often. One child wants more contacts with his brothers, and less with parents. Also, one child wants more contacts with parents, and that the frequency of contacts with the brothers remains the same. One of the children did not express their wishes regarding that subject. No child wants to terminate the existing contacts. Brother and sister who are placed in the same foster family have different views on contacts with parents.
Half of the children have the desire to establish contacts with the people that they have no contacts whit now. Three children want to establish contacts with their aunts, one of them with brother, one with grandmother, one with great-grandfather.

When it comes to the participation of children in the planning and creation of contacts, one-third of children said that they were never asked to give an opinion on the contacts, one child stated that she does not remember, while four children actively participate. Children who participate in decisionmaking believe that their wishes are respected. Four children did not comment.

"They always ask us how often, when, at what time. The people from the Center ask us. We have the freedom to tell them what we want", (girl, twelve years old).

"They ask us our opinion on what time is ok for us once a year. And we tell them our opinion and we always agree", (boy, thirteen years old).

"My grandmother asked me, and people from Center asked me.And I said that I would like to spend one weekend with dad, and one with mom. They said they would find solution with them", (boy, ten years old).

All the children were ready to talk about how they imagine that the contacts with loved ones looks like, or what would be the best possible contact. The largest number of children $(\mathrm{N}=9)$ want to joint activities with parents (going for a walk together, going to the park, amusement park, zoo, going to the sea). Children who see their parents at center for social work often talk about walk. A number of children say, that the activities and content of the contacts are not important to them, but they feel the need to be together with parent and relatives and to be happy during the contacts. Two children would like to retain the contacts as they are now, and one child does not give an accurate description but says that the contacts looked "cool".

"I'd like to go to the Sava river, to watch the boats and everything and sometimes to go to the zoo and watch the animals and to talk about how we felt when we were in the office", (girl, nine years old). "I would like all of us to get together-parents, my brother, my two cousins. And I'd like to go with them, I do not know where, for example in the shopping mall. Some where to go for a walk and to chat and to laugh together. I'd like us all to be happy", (girl, twelve years old). 


\section{Discussion of research results}

All children who participated in focus groups make contacts with some of the parents and/or relatives. However, when the number of children who make contacts is observed, most common frequency of contacts is once a month (as shown by the results of a sample of 100 children). It is concluded that there is a noticeable need for improving the organization of contacts, so that the contact not only existed, but are continuous, purposeful and predictable.

For most of the children there is a positive attitude towards contacts with parents and relatives. The fact that some of them know and cite the exact dates of contacts show the importance of contacts for children. The importance of the contacts is confirmed by the fact that children like it when adults who know their history repeat stories and events in which they participated. In this way children interpret and reinterpret themselves in the present compared events from the past, which helps them to establish continuity and to build up a picture of themselves. Feelings were the subject which was hardest for children to talked about. Before and during contacts positive emotions are dominant in children, and after contacts ambivalent feelings appear. The children are happy to have seen their loved ones, but there is also a sense of sadness that the contacts are finished. What stands out is significantly that no child wants to terminate the established contacts. Equal number of them wish for contacts frequency to remain the same, and to increase, while half of the children want to establish contacts with persons close to them with whom there is no contact now. Children have a realistic desires and proposals regarding the contacts that would be perfect for them. A desire for common activities during contacts is express most often, which indicates the importance of not only the existence but also the quality of contacts. Based on the narrative of the small number of children who had the opportunity to participate in planning and creating contacts, it has been noted how important it is to them to recognize that their opinions and wishes are respected when they have a chance to express them.

The impression of researchers is that the exchange of the focus group was a pleasant and positive experience for children. This could be seen during the discussions based on the active participation of children and spontaneity of exposure, but also in the end, when the moderators evaluated the work and feelings with them. Children state that they it was "great", "beautiful", "fun", "good."

"I feel great because, finally, I can say how I feel", (girl, nine years old).

\section{CONCLUDING REMARKS AND IMPLICA- TIONS FOR SOCIAL WORK PRACTICE WITH CHILDREN}

This study examines the views of foster children on contacts with their parents and relatives. Positive attitudes of children toward the contacts, their desire to continue contacts, proposals on how contacts can be maintained mostly the contacts with the parents and relatives of children in foster care are important issues. How contacts with parents and relatives can be a resource, not a risk to children, the involvement of children in foster care in planning and creating contacts with parents and relatives is necessary. It is necessary to give children the opportunity to express their views, wishes and feelings, and to accordingly decide on the contacts. The decision on the contacts should be based on good evaluation and factors to be taken into account in addition to the wishes of children and the purpose of the contacts, the relationship between parents and children, the safety of the child, child's age (Taplin, 2005). Also, the wishes of children should be respect as long as they do not endanger the security and safety of children. When it comes to siblings who have different attitudes, feelings and wishes in connection with contacts, contacts should be planned for each child separately. It is necessary to improve the content of contacts so the contacts do not only ful filled the form but also the essence. Based on interviews with the children it can be concluded that joint activities with parents and relatives are suited for children. The possibilities for this are limited when the contacts are held in the premises of the center for social work, more commitment of skilled workers is required in content creation as well as involvement of children and parent and relatives. Whenever possible, contacts should be integrated into the children's existing activities (school and extracurricular activities, shopping, walk) which can be realized in the presence and supervision of caseworkers and/or guardian ship authority, if it is so required for child' $s$ safety. This study has certain limitations. For the study two focus groups have been held which did not provide the opportunity for adequate saturation (O'Reilly; Parker, 2013). Also, because of the size and the selection of the sample, the results can not be generalized to all children in foster care who maintain contacts with their parents and relatives. Therefore, the results obtained in this study provide only a preliminary sketch of the situation in this area and can serve as the basis and direction for future research. 


\section{REFERENCES}

Cleaver, H. (2000). Fostering Family Contact. London: The Stationery Office.

CREATE Foundation (2001). Participation in case planning process: A consultation with children and young people in care about their experience in decision making. Retrieved fromhttp://www.create.org.au

Herrick, M. A. and Piccus, W. (2005). Sibling connections: The importance of nurturing sibling bonds in the foster care system. Children and Youth Services Review, 27 (7), 845-861.

Littner, N. (1975). The importance of the natural parents to the child in placement.Child Welfare, 54, 175-181.

Mason, J. and Gibson, C. (2004). The needs of children in care. Retrieved fromhttp://www.burnside.org.au/content/ content/The $\% 20$ needs $\% 20$ of $\% 20$ children $\% 20$ in $\% 20$ care\%20-\%20June\%2004.pdf

Ofsted, (2009). in Touch. A report of children's experience by the Children's Rights Director for England. Retrieved fromhttp://dera.ioe.ac.uk/10952/1/Keeping\%20 in $\% 20$ touch.pdf

O’Reilly, M. and Parker, N. (2013). „Unsatisfactory Saturation“: a critical exploration of the notion of saturated sample sizes in qualitative research. Qualitative Research, 13 (2), 190-197.
Quinton,D., Rushton, A., Dance, D. and Moyers, D. (1997). Contact between Children Placed Away from Home and their Birth Parents: Research Issues and Evidence. Clinical Child Psychiatry, 2 (3), 393-413.

Republički zavod za socijalnu zaštitu (2015). Sintetizovan izveštaj o radu centara za porodični smeštaj $i$ usvojenje za 2014. godinu (Report about work centers for foster care and adoption for 2014. year). Retrieved fromhttp://www.zavodsz.gov.rs/index. php?option $=$ com content\&task $=$ view\&id $=160 \&$ Item $\mathrm{id}=157$ \&lang $=1250$

Sinclair, I. (2005). Fostering Now: Messages from Research. London: Jessica Kingsley Publishers.

Taplin, S. (2005). Is All Contact between Children in Care and their Birth Parents 'Good' Contact'? Sydney: NSW Department of Community Services.

Žegarac, N. (2014). U lavirintu socijalne zaštite: pouke istraživanja o deci na porodičnom i rezidencijalnom smeštaju (In the labyrinth of social protection: lessons learnt from research on children in care). Beograd: Fakultet političkih nauka. 